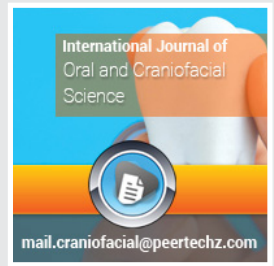

\title{
International Journal of Oral and Craniofacial Science
}

\section{Jabr Saleh Al-sanabani1 ${ }^{*}$, Essam \\ Ahmed Al-Moraissi ${ }^{2}$ and Abdulrazaq Ahmed Almaweri ${ }^{1}$}

'Assistant Professor, Department of Oral Medicine and Oral Diagnosis, Faculty of Dentistry, Saba University, Yemen.

${ }^{2}$ Assistant Professor, Department of Oral and Maxillofacial Surgery, Faculty of Dentistry, Thamar University, Yemen.

Received: 18 November, 2017

Accepted: 04 December, 2017

Published: 05 December, 2017

*Corresponding authors: Jabr AL-Sanabani, Assistant Professor, Department of Oral Medicine and Oral Diagnosis, Faculty of Dentistry, Saba University, Yemen, Tel: 777788939,

E-mail: jabralsanabani@gmail.com

Keywords: Temporomandibular disorders; TMJ sound; Helkimo index; Myofacial pain; Cross-sectional study

https://www.peertechz.com
Research Article

\section{Prevalence of Temporomandibular} Joint Disorders among Yemeni University students: A prospective, cross-sectional study

\section{Abstract}

Purpose: The aim of this study was to estimate prevalence of temporomandibular Joint disorders (TMDs), among dental university student in Yemen.

Material and methods: A prospective cross-sectional study was conducted in the Department of Oral Medicine and Oral Diagnosis, Faculty of Dentistry, Thamar University, Yemen. Study sample consisted of 207 university students (114 males and 93 females). Predictor's variables were age, gender and marital status. The outcomes variables were the signs and symptoms of TMDs using the Helkimo clinical dysfunction (Di) and anamnestic (Ai) indices.

Results: The results revealed that prevalence of TMDs among Yemeni dental students was $41.07 \%$ (mild: $14.01 \%$, sever: $27.05 \%$ ). In the clinical examination, $49.76 \%$ (mild: $20.77 \%$, moderate; $12.08 \%$ and sever; $16.91 \%$ ) showed some degree of dysfunction. Females showed a significant higher prevalence of TMDs than males. There was significant association between the dysfunction of TMD and gender $(P>$ 0.005).

Conclusion: The result of this study showed that prevalence of TMDs among Yemeni dental students was higher than some studies have reported in the literature. Also, the results revealed that majority of studied sample were not aware of the presence of their TMD

\section{Introduction}

Temporomandibular joint (TMJ) function has been the subject of considerable study for over a century, and despite voluminous literature, the multifactorial etiology of temporomandibular dysfunction is even today a cryptic issue [1].

Temporomandibular disorders (TMD) have defined as a collecting term comprising a variety of clinical signs and symptoms confined to the temporomandibular joint (TMJ) and/ or the related structures (masticatory musculature, bone and facial structures). Signs and symptoms of the TMD include a symptom as facial pain, headache, earache, and joint pain both on rest position and during jaw movement; and signs as limited jaw movement, jaw deviations, joint noises (clicking and popping), jaw locking, and dislocation. In addition, traumatic occlusion and wear of dentition due to parafunctional habits (clenching and bruxism, anxiety, stress) had been experienced in by patients with TMD $[2,3]$.
Several research and clinical diagnostic criteria were introduced have been used to diagnose the TMDs including: Helkimo index (HI) - in $11.7 \%$ research studies, criteria (RDC/ TMD) for TMDs; $23.5 \%$, craniomandibular index (CMI) $58.8 \%$, anamnesis questionnaires $35.2 \%$ [4], and Fonseca's anamnesis index (FAI) [5]. It has been report that prevalence of TMDs ranged from $20 \%$ to $50 \%$ [6], but those who seek treatments accounts about 2-7\% [7], the most affected age group varied between 20 years to 40 years with female predilection. A higher ratio of women has been seeking treatment (ranging from 3:1 to $9: 1)[8-10]$.

It has been well established, by means of epidemiological studies in which signs and symptoms of TMDs are common in adults of all ages [11]. Reports have shown that signs and symptoms of temporomandibular disorder (TMD) increase with age; however, other studies have shown a decrease in symptoms with increasing age [12]. Over a 20-year period, investigations on TMD have revealed predominately mild signs and symptoms already present in childhood. 
An increase in symptoms occurs until young adulthood, after which they level out $[4,13]$. The concept of TMD may be attributable to specific genes that are inheritable. There are evidences to suggest that anxiety, stress, and other emotional disturbances may exacerbate TMDs, especially in patients who clinically experience chronic pain $[3,14]$.

Nevertheless, the cause of the signs and symptoms of TMDs is not clearly understood and various opinions on their etiology have been offered. It is evident from the numerous epidemiologic studies on the occurrence of temporomandibular disorders that signs of temporomandibular disorders appear in about $60 \%-70 \%$ of the general population and yet only about one in four people with signs are actually aware of or report any symptoms [15]. The frequency of severe disorders that are accompanied by headache and facial pain characterized by urgent need of treatment is $1 \%-2 \%$ in children, about $5 \%$ in adolescents and 5\%-12\% in adults [16]. A non-patient population has been reported prevalence rates vary broadly (from $26 \%$ to $50 \%$ ) [17].

The Helkimo index was one of the first to be referred to in the literature as having the reliability to identify signs and symptoms of TMD. Because it has the following advantages including: 1) Its allow to collect a large number of information in a short period of time; 2) it is a low-cost application; 3) Easy for perception-based evaluation ;4) does not influence the appraiser in obtaining answers; 5) a simple self-administered questionnaire would offer the advantage of faster application and, thus, low cost. This makes epidemiological surveys and treatment follow-up by using this index is more feasible. An additional advantage is that a self-applied questionnaire would provide a severity index with less influence from the examiner and less variability in the measures $[5,11,17]$.

Helkimo reported that prevalence of TMD varied from $12 \%$ and $57 \%$ for anamnestic symptoms and between $28 \%$ and $88 \%$ for clinical signs [18]. In Asian population, $43 \%$ of Taiwanese university students had a prevalence of one or more signs of TMD [19]. About $19 \%$ had anamnestic symptoms and that over $36 \%$ showed clinical sign in university students have reported by Jagger [20].

A higher prevalence of TMD has been reported among male university students in Riyadh, Saudi Arabia (46.8\%) [21]. another study in north Saudi university students showed that prevalence of TMD was higher (94.7\%) [22]. Whilst, a low rate of $\operatorname{TMD}(25.4 \%)$ among students was estimated in Arab students at Gulf Medical University Ajman, UAE [23]. Additionally, the prevalence of TMD in Indian university students was (45.16\%) and showed women slightly higher than men $36.58 \%$ and $31.48 \%$ respectively) $[2,14]$. A higher prevalence of TMD among the university students in Brazil was $57.7 \%$ and showed the women higher prevalence than men $(68.7 \%$ and $48.2 \%)$ [24].

Others epidemiological studies estimated the prevalence of TMDs in various communities including: Southern Portugal (25.2 \%) [16]. Caucasian population (23.78\% in male and 25.32 in female) [25], Syrian (28\%) [26].
A higher prevalence rate of TMDs has been documented among university Students in Sudan and Jordan $(77.8 \%$ and $68.6 \%$ respectively) $[15,27]$.

Up to date, there is no study estimated prevalence rate of the TMDs among Yemeni population. To the best of author's knowledge, this is the first epidemiological study identifying the rate of signs and symptoms of TMDs among Yemeni university students. Therefore, authors of this study aimed to estimate prevalence rate of TMDs among Yemeni university students, using Helkimo anamnestic index and dysfunction index.

\section{Material and Methods}

\section{Study design}

A cross-sectional, prospective study was conducted in the Department of Oral Medicine and Oral Diagnosis, Faculty of Dentistry, Thamar University, Dhamar, Yemen. An approval for this study was obtained from the scientific ethic committee.

\section{Study sample}

The study sample comprised 207 dental students studying at the following institutions: from the Faculty of Dentistry, Thamar University and Faculty of Dentistry, Saba University.

\section{Inclusion criteria}

1. Dental students of the Thamar and Saba University

2. Both male and female were including

3. Age ranged from 18 to 26 years with mean age 22.4 age

4. Students signed a consent form agreeing to participate in the study.

\section{Exclusion criteria}

1. Students with pervious history of TMDs like: fibromyalgia, trigeminal neuralgia, burning mouth syndrome, atypical facial pain, migraine, atypical odontalgia, cervical, neuropathic pain and those with a history of previous TMD treatment were excluded from the study

2. Those students who have not signed the consent form.

3. Students with history of systemic, musculoskeletal or neurological disorders

\section{Student with history of orthodontic treatment}

\section{Predictors and outcomes variable}

\section{Interview}

The subjective symptoms were obtained by asking the students the following questions with adequate explanation as needed which history of emotional stress, maxillofacial surgery, orthodontic treatment and history of trauma by dental work. Then information about related factors were obtained and recorded, which included headache more than twice a week or 
more, previous trauma to head and neck and oral parafunctions, the subjects was asked if $s$ /he frequently did one or more of the following oral habits (grinding, clenching, nail-, object-, lipcheek biting, chewing gum, chewing on one side and sleeping on their face.

Age, gender and marital status are the predictor >s variables. The outcomes variables were the signs and symptoms of TMDs, assessing through questionnaire using a Helkimo index and dysfunction of TMJ assessed through clinical examination using a dysfunction index [28].

To assess symptoms of the TMDs using anamnestic Helkimo index (Ai), it was subdividing into three parts namely: First, (Aio) involves a complete absence of symptoms. Second: (AiI), involves a mild symptom including, one or more of the following symptoms were reported in anamnesis: joint sound, feeling of fatigue and feeling of stiffness of the jaws on awaking. Third, (AiII), involves severe symptoms of dysfunction, one or more of the following symptoms were reported in anamnesis as difficulty in opening the mouth widely, locking, subluxation, pain on movement of the mandible, facial and jaw pain, pain and tiredness on chewing (Table 1).

\section{Clinical Examination}

All clinical examinations and assessments for articular and masticatory components of the TMJ was performed by the first author (J S A). A clinical examination was conducted to assess severity of clinical signs TMDs, based on the clinical dysfunction index by Helkimo (Di). The dysfunction index was subdividing into 4 categories $(\mathrm{Dio}=$ free symptoms, $\mathrm{DiI}=$ mild dysfunction, DiII $=$ moderate dysfunction and DiIII $=$ sever dysfunction $)$. Each category was obtaining an index value according to clinical examination for the following variables 1) maximal mouth opening; 2) TMJ function as clicking, crepitation, deviation, locking, luxation; 3) Masticatory muscle pain or tenderness; 4) TMJ pain during palpation and mandibular movement (Table 2).

\section{Statistical analysis}

Statistical analysis was performed using SPSS v.22.0 (IBM, USA). To Descriptive statistics were performing to all variables in the study. After that, Chi-squared Test of Independence was applied in order to evaluate associations between the occurrence of TMD and gender, age, and severity of the TMDs through Helkimo index.

In order to satisfy the requirements of applicability of Chisquared Test for Independence, the variable TMD was grouped into absence and presence (included mild, moderate, and severe TMD).

\section{Results}

A total of 207 dental students $(114,55.07 \%$ was male and 93, $44.93 \%$ was female) were enrolled in this a prospective, cross sectional study. All participants were categorized into three groups: 1) 18 to 20 years (include seven participants, 3.38 $\%$; 2) 21 to 23 years (include 98 participants, $47.34 \%$ ); 3) 24 to 26 years (include 102 participants, $49.28 \%$ ).
Prevalence of the symptoms of TMD based on anamnestic index (Ai)

The prevalence of TMD was observed in $41.07 \%(\mathrm{n}=85)$ and $58.93 \%(n=122)$ was free of TMDs, $14.01 \%(n=29)$ had a mild TMDs and $27.05 \%(n=56)$ a sever TMDs. (Figure 1$)$.

Of $41.07 \%(\mathrm{n}=85)$ whose had TMDs, $18.35 \%(\mathrm{n}=38)$ and $22.70 \%(n=47)$ were male and female respectively. There was a significant association between TMD prevalence and gender $(\mathrm{P}<0.005)$. (Figure 2).

Severity of the TMDs based on clinical dysfunction index (Di)

In respect of clinical dysfunction of TMD, $49.76 \%$ ( $\mathrm{n}=$ 103), had one or more signs of TMD dysfunction (TMJ pain and clinking, deviation and limited mouth opening, masticatory muscle tenderness). Of $49.76 \%$, whose had one or more

Table 1: Anamnestic Helkimo index (Ai).

Grading

Explanation

Ai0 Free of any symptoms

TMJ sounds

Fatigue in the jaws Stiffness in the jaws on awakening or on movement of the lower jaw Difficulties in opening mouth wide Locking Luxations

Aill Pain on movement of the mandible Pain in the region of the TMJ or masticatory muscles

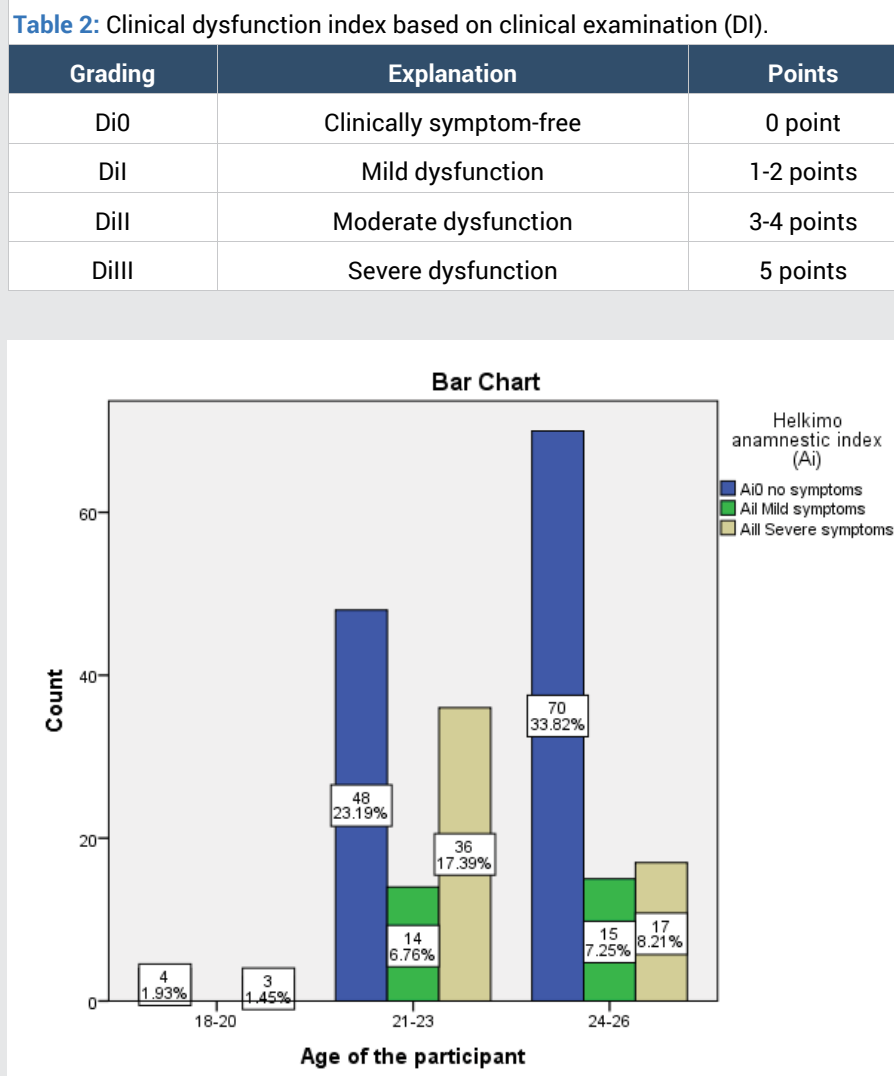

Figure 1: Association between prevalence of TMDs (based on anamnestic index) and age groups. 
TMDs, 20.77 ( $\mathrm{n}=43$ ) had, mild TMD dysfunction (11.11 \% were females and $9.66 \%$ were males $), 12.08(n=25)$ had a moderate TMD dysfunction ( $7.73 \%$ were females and 4.35 were males) and $16.91 \%(n=35)$ had a severe TMD dysfunction (10.63\% were females and $6.28 \%$ were males $)$. A $50.24 \%(n=104)$ were a free of symptoms. Females $(29.45 \%, \mathrm{n}=61)$ were had a greater severity of TMD than males $(20.29 \%, n=42) .7 .25 \%$. (Figure 3 ).

There was significant association between the TMD dysfunction (Di) of TMD and gender ( $\mathrm{P}>0.005)$.

\section{Discussion}

To the best of author's knowledge, there has been no study estimated the prevalence and severity of the TMDs among Yemenis population. The objective of present study

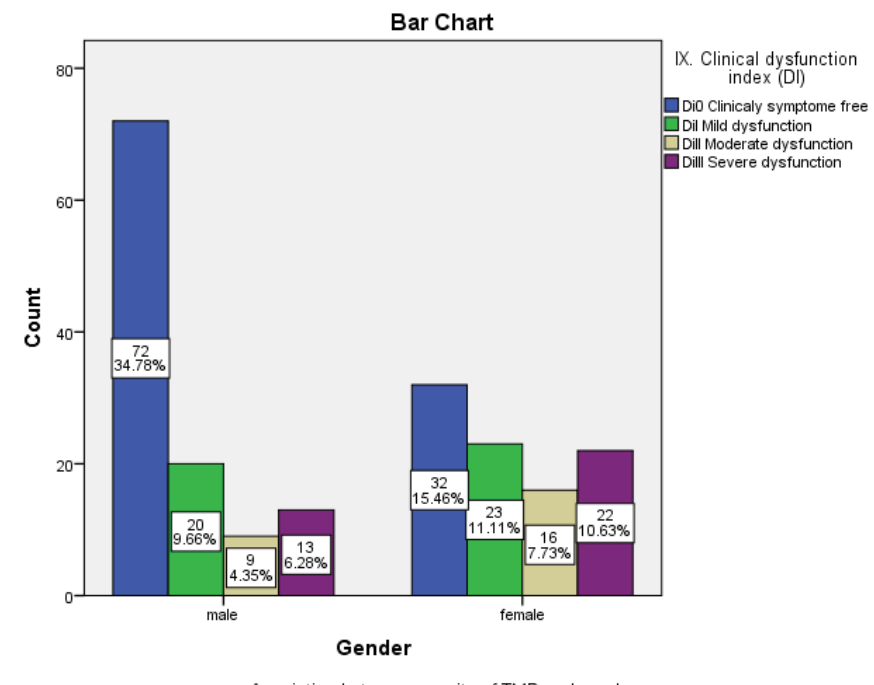

Asociation between severity of TMD and gender

Figure 2: Association between prevalence of TMDs (based on anamnestic index) and gender.

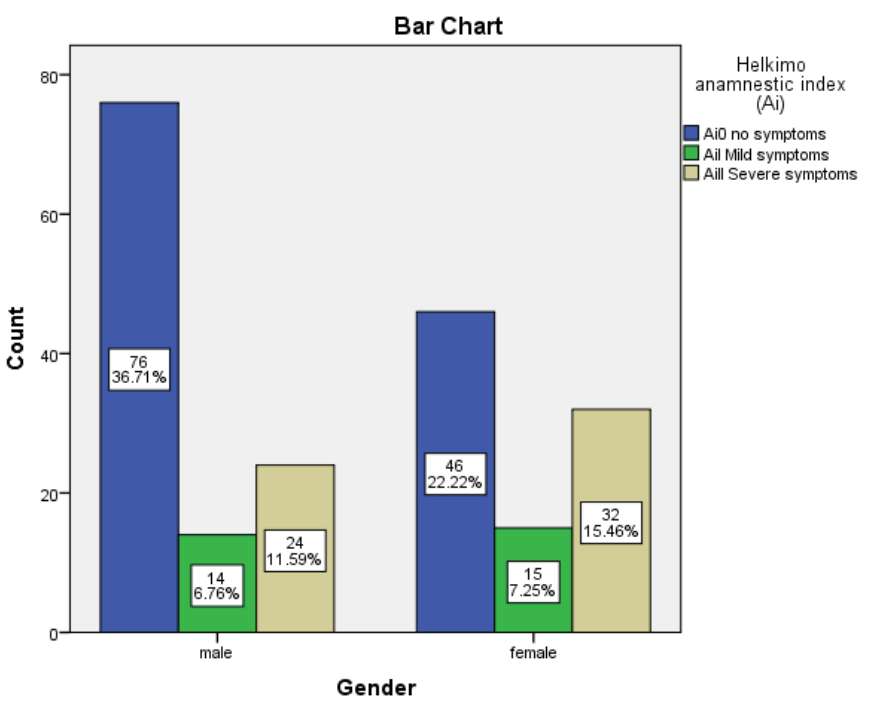

Assocaition between prevelance of TMD and gender

Figure 3: Association between severity of TMDs (Di) and gender. was to identify prevalence of TMDs among Yemeni university students, using Helkimo anamnestic index and dysfunction index. The main key findings of this study were that, prevalence of TMD was $41.06 \%(n=85)$. There was a significant association between TMD prevalence and gender $(\mathrm{P}<0.005)$. This is in consistent with others studies $[1,15,27,29,30]$, and inconsistent with others reports (slightly lower than our results) $[10,16,24,31,32]$, In contrast some studies reported a higher rate of signs and symptoms of TMDs in compared to our finding [22,32-34].

Regarding prevalence of TMDs in male and female population, there was slightly higher prevalence of TMDs in student female $(22.70, \mathrm{n}=47)$, than male gender $(18.35 \%, \mathrm{n}=$ 38). This agrees of majority of previous studies [10,24,35-39], and in disagreement with others reports $[14,26,33,40]$.

The discrepancy between our results and others previous studies may be due to different racial, cultural and economic environments.

Based on anamnestic Helkimo index, a majority of studied sample were suffered of sever TMDs $(27.1, \mathrm{n}=56)$, this is a higher and inconsistent with previous studies $[14,41]$.

The prevalence of clinical dysfunction in our study was 49.876 \% (Dio: $50.24 \%$, DiI: $20.8 \%$, DiII; $12.8 \%$ and DiIII; $16.91 \%)$. This is similar to others studies $[36,42-46]$. There was significant association between the dysfunction of TMD and gender $(\mathrm{P}>0.005)$. This in accordance with other previous studies [43].

Limitations of the present study were: 1) Helkimo index has been used to assess prevalence and severity of TMDs, it does not serve for diagnosis and classify of TMD. The result given through using of this index are limited to the identification of the severity of signs and symptoms of TMD

Strengths of this study were: 1) both subjective (Ai, anamnestic index) and objective (Di, dysfunction index) have been investigated; 2) study sample was collected from two separated governorates in Yemen. Thamar University is a governorate located at middle of country, while Saba University located in Sanaa (capital of country). Thus, study sample consisted of students coming from all regions in Yemen. Therefore, this is meant that results of this study can be generalized and fulfilled the principal of internal validity of good study.

The results of this study confirm that prevalence of TMD are more frequent among female that male. This is accordance with many studies $[14,36,41-48]$. The best explanation for that is hormonal factors are believed to account for at least some of the gender difference in prevalence rates. 45 Some studies have assessed the role of hormonal fluctuations in the frequency or intensity of musculoskeletal pains, such as TMD, where episodes tend to be longer than for headache. Dao et al. showed on variability of myofascial pain of TMD over three menstrual cycles in 12 female subjects. Consumers of oral contraceptives tended to show less variable pain intensity levels, and fewer 
pain-free days than women suffering hormonal fluctuations related to their naturally occurring menstrual cycles; nevertheless, the differences were not statistically significant and a predominant temporal pattern could not be discerned in this small sample [49]. In the normal menstrual cycle, estrogen levels are at their lowest during menses. Estrogen secretion rises gradually during the early part of the follicular phase and then exponentially in the days before ovulation. Ovulation happens about 10-12 $\mathrm{h}$ after the LH peak, around Day 14 in the 'typical' menstrual cycle. There is a precipitous decrease in estrogen in the days following ovulation and then a gradual increase during the early to mid-luteal phase. Estrogen then drops again during the late luteal phase just prior to menses [50].

As far as, this study assessed prevalence of TMD among of Yemeni population, disc positions were not investigated to identify causes of TMJ clicking. This is because unavailability of magnetic resonance image. Additional disadvantages of this study the external validity because presence of khat chewing habits among Yemeni population will increase in the chance of development of TMD due to increased total number of chewing hours per day. Recently study showed that there was significant difference in prevalence of TMD between khat chewer students and non khat chewer students [51].

The etiology of TMDs has been associated to several factors, namely traumatic injury, immune-mediated systemic disease, neoplastic, emotional stress, occlusal discrepancies, malocclusion or loss of teeth, postural changes, disease of the masticatory musculature and adjacent structures, extrinsic and intrinsic changes of TMJ structure, bruxism , tooth clenching habits, or a combination of such factors [52,53]. Prosthodontic rehabilitation, orthodontic treatment, orthognathic surgery, and mandibular fractures have been associated with TMJ changes and worsening of existing TMD [54]. Loading, altered jaw position, and mechanical stress in response to the aforementioned treatments induce morphological changes in the TMJ, due to its inherent adaptive capacity [14].

Concerning a TMD assessment tool, the research diagnostic criteria for temporomandibular disorders (RDC/TMDs) is universally accepted tool, which have since been used in multiple clinical and epidemiological investigations [55]. Recently [56], a proposed a new refinement and modification version of the RDC/TMDs, known as the Diagnostic Criteria for Temporomandibular Disorders (DC/TMD). They claim that the DC/TMD includes a valid and reliable screening questionnaire, as well as diagnostic algorithms for the most common painrelated TMDs. Despite their advantages, the RDC/ TMD and $\mathrm{DC} / \mathrm{TMD}$ are quite cumbersome assessment tools in that they require the individual to be present in order to render a TMD diagnosis, and they are difficult to use on large samples. The so called Fonseca's anamnestic index (FAI) is a self-administered questionnaire for the non-patient population. It has been proposed as a low-cost, easily applied alternative TMD assessment tool and can be used by both general practitioners and epidemiologists [57], in the present study, Helkimo anamnestic index and dysfunction index was applied to assess prevalence of TMD. This is similar to most previous studies.
Emotional and psychological stress is also an important factor predisposing to the TMD development. The studied student population is particularly susceptible to the impact of this factor [58]. Psychological stressors may involve large number of duties, the pressure of getting a well education, an uncertain future, low income, living far away from house, and working in a foreign environment. Additionally, students also face social, emotional, physical, and family problems [59]. This is study did not assess the psychological factors in developing TMD Because the Helkimo index specified on certain points. Base on present literature this percentage could reach $72 \%$ [60], or even $90 \%$ [61], in student sample. It has been concluded that being under stress increases the activity of the masticatory muscles, which subsequently results in TMD [61].

\section{Conclusion}

In conclusion, the results of the present study revealed that among dental university students was $41.07 \%$ of studied sample showed symptoms (Ai) of TMD. Also, this study has shown that $49.76 \%$ of studied sample revealed some degree of dysfunction (Di).

Further investigations with calculation of sample size and using diagnostic research criteria to assess prevalence and severity of TMD among Yemeni population are needed before a final conclusion can be drawn.

\section{References}

1. Modi P, Shaikh SS, Munde A (2012) A Cross Sectional Study of Prevalence of Temporomandibular Disorders in University Students. Inter J Scien and Res Pub 2:1-3. Link: https://goo.gl/5MZbp1

2. Sakrania H, Ghandhib D, Kamalc AT (2015) Prevalence of signs and symptoms of temporomandibular disorders in different malocclusion groups. POJ 7: 2-7 Link: https://goo.gl/XgJB2v

3. Milanez Oliveira FB, Rocha Paula AB (2016) Association between Temporomandibular Dysfunction and Depression in People Living with HIV/ AIDS. International Archives of Medicine 9: 393 Link: https://goo.gl/xt879F

4. Sena MF, Mesquita KS, Santos FR, Silva FW, Serrano KV (2013) Prevalence of temporomandibular dysfunction in children and adolescents. Rev Paul Pediatr 31: 538-545. Link: https://goo.gl/1Wdbde

5. Campos JADB, Gonçalves DAG, Camparis CM, Speciali JG (2009) Reliability of a questionnaire for diagnosing the severity of temporomandibular disorder Rev Bras Fisioter 13: 38-43. Link: https://goo.gl/Xru6ih

6. Graber TM, Rakosi T, Petrovic AG (2009) Functional Analysis-Examination of Temporomandibular Joint and Condylar Movement. In: Dentofacial Orthopedics with Functional Appliances, 2nd Edition, Mosby, St. Louis, 135140. Link: https://goo.gl/GTYNkJ

7. Köhler AA, Hugoson A, Magnusson T (2013) Clinical signs indicative of temporomandibular disorders in adults: time trends and associated Factors. Swedish Dental Journal 37: 1-11. Link: https://goo.gl/4CP4s2

8. Guimarães TB, Ferreira-Cabrini MB, Quaglio $\mathrm{CL}$, Guimarães $\mathrm{AS}$, Smith $\mathrm{RL}$, Antunes SV, et al. (2015) Temporomandibular disorder: prevalence among hemophiliac patients. Int. J. Odontostomat. 9: 295- 300. Link: https://goo.gl/7Y8sH9

9. Bagis B, Ayaz EA, Turgut S, Durkan R, Özcan M (2012) Gender difference in prevalence of signs and symptoms of temporomandibular joint disorders: a retrospective study on 243 consecutive patients. Int. J Med Sci 9: 539-544 Link: https://goo.gl/WpKG21 
10. Manfredini D, Chiappe G, Bosco M (2006) Research diagnostic criteria for temporomandibular disorders (RDC/TMD) axis I diagnoses in an Italian patient population. J Oral Rehabil 33: 551-558. Link: https://goo.gl/5R5NWh

11. Kalanzi D, Osman YI, Shaikh A (2005) Prevalence of Sign and Symptoms of the Temporomandibular Join Dysfunctions in Subjects with Different Occlusion Using Helkimo Index. Thesis for Degree of Masterscience in Restorative Dentistry, University of Western Cape, Cape Town Link: https://goo.gl/tj7avB

12. Hiltunen K, Schmidt-Kaunisaho K, Nevalainen J, Närhi T, Ainamo A (1995) Prevalence of Signs of Temporomandibular Disorders among Elderly Inhabitants of Helsinki, Finland. Acta OdontolScand 53: 20-23. Link: https://goo.gl/Ug2QZc

13. Magnusson T, Egermarki I, Carlsson GE (2005) A Prospective Investigation over Two Decades on Signs and Symptoms of Temporomandibular Disorders and Associated Variables. A Final Summary. Acta Odontol Scand 63: 99-109 Link: https://goo.gl/SxF7MT

14. Majumder K, Sharma S, JK DR, Siwach V, Arya V, et al. (2015) Prevalence and Sex Distribution of Temporomandibular Disorder and Their Association with Anxiety and Depression in Indian Medical University Students. International Journal of Clinical Medicine 6: 570-578. Link: https://goo.gl/wabLV3

15. Ryalat S, Baqain Z, Amin W, Sawair F, Samara O, et al. (2009) Prevalence of Temporomandibular Joint Disorders among Students of the University of Jordan. J Clin Med Res 1:158-164. Link: https://goo.gl/i8jqcj

16. Minghelli B, Cardoso I, Porfírio M, Gonçalves R, Cascalheiro S, et al. (2014) Prevalence of Temporomandibular disorder in children and adolescents from public schools in Southern Portugal. North Am J Med Sci 6:126-132. Link: https://goo.gl/Zxt8NT

17. Sena MF, Mesquita KS, Santos FR, Silva FW, Serrano KV (2013) Prevalence of temporomandibular dysfunction in children and adolescents. Rev Paul Pediatr 31: 538-545. Link: https://goo.gl/VqPHSW

18. Vojdani M, Bahrani F, Ghadiri P (2012) the study of relationship between reported temporomandibular symptoms and clinical dysfunction index among university students in Shiraz. Dent Res J (Isfahan) 9: 221-225. Link: https:// goo.gl/j5nUgF

19. Lee JY, Kim YK, Kim SG, Yun PY (2013) Evaluation of Korean teenagers with temporomandibular joint disorders. J Korean Assoc Oral Maxillofac Surg 39 231-237. Link: https://goo.gl/rWe2hX

20. Karatas O, Peker K, Balık A, Uysal O, Tuncer EB (2013) Identifying potential predictors of pain-related disability in Turkish patients with chronic temporomandibular disorder pain. J Headache Pain 14: 17. Link: https://goo.gl/mAh87S

21. Habib SR, Al Rifaiy MQ, Awan KH, Alsaif A, Alshalan A, et al. (2014) Prevalence and severity of temporomandibular disorders among university students in Riyadh. Saudi Dent J 27: 125-130. Link: https://goo.gl/s671yQ

22. Zwiri AM, Al-Omiri MK (2016) Prevalence of temporomandibular join disorder among North Saudi University students. Cranio. 34: 176-181. Link https://goo.gl/M6KF3p

23. Elyasi M, Majeed S, Elyassi M, Aziz A, Rashid K, et al. (2016) Prevalence of temporomandibular joint disorder among Gulf Medical University students. Gulf Medical Journal 5: S123-S130. Link: https://goo.gl/Dn6wVb

24. Cabral RP, Moiolli-Rodrigues ME, Motta FLK, Souza Motta FCK, da Silva JR, et al. (2016) Temporomandibular Disorder in University Students of the Parque das Rosas Campus, Universidade Estácio de Sá That Practice Sports. Health 8: 18-23. Link: https://goo.gl/YeE89t

25. Tecco S, Crincoli V, Di Bisceglie B, Saccucci M, Macrl M, et al. (2011) Signs and symptoms of temporomandibular joint disorders in Caucasian children and adolescents. Cranio 29: 71-79. Link: https://goo.gl/tx2kA1
26. Issa N, Baherly N, Mayhoube M (2015) Prevalence of Symptoms of Temporomandibular Joint Disorder in Lattakia-Syria, 1: 23-28. Link: https://goo.gl/xEwvtb

27. Ahmed LI, Abuaffan AH (2016) Prevalence of Temporomandibular Joint Disorders among Sudanese University Students. J Oral Hyg Health 4: 200. Link: https://goo.gl/v5Mwdm

28. Toscano $P$, Defabianis $P$ (2009) Clinical evaluation of temporomandibular disorders in children and adolescents: a review of the literature. Eur J Paediatr Dent 10: 188-192. Link: https://goo.gl/UcPZrc

29. Modi P, Shaikh SS, Munde A (2012) A Cross Sectional Study of Prevalence of Temporomandibular Disorders in University Students. International Journal of Scientific and Reserach Publications 2: 9-11. Link: https://goo.gl/zyqZvB

30. Gopal SK, SRS, Vardhan BGH (2014) Prevalence of Temporomandibular Joint Disorders in Symptomatic and Asymptomatic Patients : A Cross-Sectional Study 1: 14-20. Link: https://goo.gl/Kex7mE

31. Hama AM, Mahmood DK (2016) Development Research Evaluation of Temporomandibular Joint Disorders in partially edentulous patients International Journal of Development Research 6: 8531-8533.

32. Murrieta J, Alvarado E, Valdez M, Orozco L, Meza J, et al. (2016) Prevalence of temporomandibular joint disorders in a Mexican elderly group. Journal Oral of Research 5: 13-18. Link: https://goo.gl/jNMQQK

33. Oliveira A, Dias E, Contato R, Berzin F (2006) Prevalence Study of Signs and Symptoms of Temporomandi- bular Disorder in Brazilian College Students. Brazilian Oral Research 20: 3-7. Link: https://goo.gl/x8g9pm

34. Tanboga I, Durhan MA, Durmus B, Marks LA (2014) Temporomandibula Disorders in Young People with an Intellectual Disability: Prevalence of Signs and Symptoms. Eur J Paediatr Dent 15: 349-354. Link: https://goo.gl/s5Zrn5

35. Vedolin GM, Lobato VV, Conti PC, Lauris JR (2009) the Impact of Stress and Anxiety on the Pressure Pain Threshold of Myofascial Pain Patients. J Oral Rehabil 36: 313-321. Link: https://goo.gl/VF5jgq

36. Pedroni CR, Oliveira AS, Guaratini MI (2003) Prevalence Study of Signs and Symptoms of Temporomandi- bular Disorders in University Students. Journal of Oral Rehabilitation 30: 283-289. Link: https://goo.gl/DMhHFP

37. Feteih RM (2006) Signs and Symptoms of Temporomandibular Disorders and Oral Parafunctions in Urban Saudi Arabian Adolescents: A Research Report. Head Face Med 2: 25. Link: https://goo.gl/NhkkMu

38. Pollard H, Fernandez M (2004) Spinal Musculoskeletal Injuries Associated with Swimming: A Discussion of Technique. Australian Chiropractors and Osteopaths 12: 72-80. Link: https://goo.gl/JyyqZY

39. Yuill E, Howitt SD (2009) Temporomandibular Joint: Conservative Care of TMJ Dysfunction in a Competitive Swimmer. J Can Chiropr Assoc 53: 165-172. Link: https://goo.gl/JenRE4

40. Bonjardim LR, Lopes-Filho RJ, Amado G, Albuquerque RL, Goncalves SR (2009) Association be- tween Symptoms of Temporomandibular Disorders and Gender, Morphological Occlusion, and Psychological Factors in a Group of University Students. Indian J Dent Res 20: 190-194. Link: https://goo.gl/axw99K

41. Iturriaga V, Navarro P, Cantín M, Fuentes R (2012) Prevalence of vertical condilar asymmetry of the temporomandibular joint in patients with signs and symptoms of temporomandibular disorders. Int J Morphol 30: 315-321. Link: https://goo.gl/Mmr53W

42. kassa M, bakry A, Salem WS (2015) The Incidence of Temporomandibula Joint Disorders among Dental Students in Aljouf University, KSA. International Invention Journal of Medicine and Medical Sciences 2: 5-11. Link: https://goo.gl/W5rZuy 
43. Vojdani M, Bahrani F, Ghadiri P (2012) the study of relationship between reported temporomandibular symptoms and clinical dysfunction index among university students in Shiraz. Dent Res J (Isfahan) 9: 221-225. Link: https:// goo.gl/eiUkwL

44. DeRossi S, Stoopler E, Sollecito T (2004) Temporomandibular Disorders and Migraine Headache: Comorbid Conditions? The Internet Journal of Dental Science. 2: 1. Link: https://goo.gl/6UEi8m

45. Kobs G, Bernhardt O, Kocher T, Meyer G (2005) Oral parafunctions and positive clinical examination findings. Stomatologija 7: 81- 83 Link: https://goo.gl/nTEqn2

46. Nassif NJ, Al-Salleeh F, Al-Admawi M (2003) the prevalence and treatment needs of symptoms and signs of temporomandibular disorders among young adult males. J Oral Rehabil 30: 944-950 Link: https://goo.gl/o1nEvg

47. LeResche L, Mancl L, Sherman JJ, Gandara B, Dworkin SF (2003) Changes in temporomandibular pain and other symptoms across the menstrual cycle. Pain 106: 253-261. Link: https://goo.gl/cMQoZz

48. Koidis PT, Zarif A, Grigoriadou E, Garefs P (1993) E-ect of age and sex on craniomandibular disorders. The Journal of Prosthetic Dentistry 69: 93-101. Link: https://goo.gl/549vys

49. Dao TT, Knight K, Ton-That V (1998) Modulation of myofascial pain by the reproductive hormones. J Prosthet Dent 79: 663-70. Link: https://goo.gl/NZeAWc

50. Speroff L, Glass RH, Kase NG (1994) Regulation of the menstrual cycle. In: Clinical gynecologic endocrinology and infertility, 5th ed., Baltimore, MD Williams \& Wilkins 1994: 183-220. Link: https://goo.gl/14FgqN

51. Al Moaleem MM, Okshah AS, Al-Shahrani AA, Alshadidi AA, Shaabi FI, et al. (2017) Prevalence and Severity of Temporomandibular Disorders among Undergraduate Medical Students in Association with Khat Chewing. J Contemp Dent Pract 18: 23-28. Link: https://goo.gl/HcERcB

52. de Santis TO, Motta LJ, Gonzalez DAB, Ferrari RAM, Fernandes KPS, et al (2014) Accuracy study of the main screening tools for temporomandibular disorder in children and adolescents. J Bodyw Mov Ther 18: 87-91. Link: https://goo.gl/QKH5sn

53. Manfredini D, Lobbezoo F (2010) Relationship between bruxism and temporomandibular disorders: a systematic review of literature from 1998 to 2008. Oral Surg Oral Med Oral Pathol Oral Radiol Endod 109: e26-e50. Link: https://goo.gl/KwUs4V

54. Al-Moraissi EA, Wolford LM, Perez D, Laskin DM, Ellis E (2017) Does Orthognathic Surgery Cause or Cure Temporomandibular Disorders? A Systematic Review and Meta-Analysis. Link: https://goo.gl/6uZorF

55. Dworkin SF, LeResche L (1992) Research diagnostic criteria fo temporomandibular disorders: review, criteria, examinations and specifications, critique. J Craniomandib Disord 6: 301-355. Link: https://goo.gl/DXt9Tc

56. Schiffman E, Ohrbach R, Truelove E, Look J, Anderson G, et al. (2014) Diagnostic Criteria for Temporomandibular Disorders (DC/TMD) for clinical and research applications: recommendations of the international RDC/TMD Consortium Network* and Orofacial Pain Special Interest Group. J Oral Facial Pain Headache 28: 6-27. Link: https://goo.gl/wLhHjN

57. Da Fonseca DM, Bonfante G, Valle AL, de Freitas SFT (1994) Diagno sticopelaanamnese da disfunc, a ocraniomandibular. Rev. Gauch de Odontol 4: 23-32.

58. Yap AUJ, Dworkin SF, Chua EK, List T, Tan KBC, et al. (2003) Prevalence of temporomandibular disorder subtypes, psychologic distress, and psychosocial dysfunction in Asian patients. Journal of Orofacial Pain 17 21-28. Link: https://goo.gl/zdwGfB

59. Manfredini D, Lobbezoo F (2009) Role of psychosocial factors in the etiology of bruxism. J Orofac Pain 23: 153-166. Link: https://goo.gl/xPuaCU

60. Eswi AS, Radi S, Youssri H (2013) Stress/ stressors as perceived by baccalaureate Saudi nursing students. Middle East Journal of Scientifc Research 14: 193-202. Link: https://goo.gl/ZpQtp1

61. Shaikh BT, Kahloon A, Kazmi M, Khalid H, Nawaz K, et al. (2004) Students, stress and coping strategies: a case of Pakistani Medical School. Educ Health (Abingdon) 17: 346-353. Link: https://goo.gl/QMjW4L

Copyright: (c) 2017 Al-sanabani JS, et al. This is an open-access article distributed under the terms of the Creative Commons Attribution License, which permits unrestricted use, distribution, and reproduction in any medium, provided the original author and source are credited. 